\title{
Multidisciplinary telephone conferences about medication therapy after discharge of older inpatients: A feasibility study
}

\section{Lene Vestergaard Ravn-Nielsen ( $\sim$ Lene.Ravn-Nielsen@rsyd.dk)}

Hospital Pharmacy Funen, Odense University Hospital, Odense, Denmark and OPEN, Open Patient data Explorative Network, Odense University Hospital, Odense, Denmark https://orcid.org/0000-0001-9109-3270

\section{Alaa Burghle}

Hospital Pharmacy Funen, Odense University Hospital, Odense, Denmark and dDepartment of Public Health, Clinical Pharmacology and Pharmacy, University of Southern Denmark, Odense, Denmark

\section{Palle Mark Christensen}

General Practice, Otterup, Denmark

\section{Faruk Coric}

Hospital Pharmacy Funen, Odense University Hospital, Odense, Denmark

\section{Trine Graabæk}

Hospital Pharmacy Funen, Odense University Hospital, Odense, Denmark and Department of Public Health, Clinical Pharmacology and Pharmacy, University of Southern Denmark, Odense, Denmark

\section{Jolene Pilegaard Henriksen}

Hospital Pharmacy Funen, Svendborg Hospital, Svendborg, Denmark

\section{Fjóla Karlsdóttir}

Hospital Pharmacy Funen, Odense University Hospital, Odense, Denmark

\section{Jens-Ulrik Rosholm}

Geriatric Department, Odense University Hospital, Odense, Denmark

\section{Anton Pottegård}

Hospital Pharmacy Funen, Odense University Hospital, Odense, Denmark and Department of Public Health, Clinical Pharmacology and Pharmacy, University of Southern Denmark, Odense, Denmark

\section{Research Article}

Keywords: Multidisciplinary communication, telephone conferences, continuity of care, multimorbidity, medication review

Posted Date: March 10th, 2021

DOI: https://doi.org/10.21203/rs.3.rs-311274/v1

License: (c) (1) This work is licensed under a Creative Commons Attribution 4.0 International License. Read Full License 
Page $2 / 19$ 


\section{Abstract}

Background Studies have shown poor post-discharge implementation of changes made to patients' medication during admission by the general practitioner.

Objective To assess the feasibility of conducting telephone conferences to deliver information about changes in older patients' medications from the hospital to the general practitioners.

Setting Danish routine healthcare setting including patients admitted to departments of Geriatric medicine at Odense University Hospital and Svendborg Hospital.

Method Telephone conferences between pharmacists, geriatricians, and general practitioners were based on a review of the patient's medication therapy during hospital stay. Older polypharmacy patients were eligible for inclusion. To explore perspectives on the feasibility of telephone conferences, interviews were conducted with pharmacists, geriatricians and general practitioners. Interviews were analyzed using systematic text condensation.

Main outcome measure The proportion of telephone conferences conducted.

Results A total of 113 patients were included. Medication summaries were sent to the general practitioner for 82 patients (75\%), thus eligible for telephone conferences. A total of $40(49 \%)$ telephone conferences were conducted. The main reasons for conferences not being conducted were general practitioners not wanting to participate or not returning the calls from the pharmacists. The themes from the qualitative analysis were: Project operations, the telephone conference and cross-sectorial collaboration.

The participating general practitioners, pharmacists and geriatricians expressed varied benefit from the conferences and agreed that telephone conferences were relevant and useful for complex patients.

Conclusion Telephone conferences between geriatricians, general practitioners and pharmacists were only possible for half of the patients and seemingly mainly relevant for complex patients.

\section{Impact On Practice}

- Telephone conferences make it easier to explain reasons and argumentation for changes in medication made during hospitalization, thus making it easier for the general practitioner to get and maintain an overview of current medication therapy after discharge.

- Telephone conferences is a possible transitional pathway for better multi-professional dialogue across primary and secondary care, which enhances the clarity of roles required to improve the quality of medication therapy and e.g. prevent resumption of inappropriate medication.

- Because participants had experienced the telephone conferences as very time consuming and difficult to fit in to the daily clinical setting, telephone conferences should only be prioritized for complex patients.

\section{Introduction}


The transition from hospital to primary care constitutes a critical phase in older patients' medication therapy

[1-4] and medication related harm after discharge is common [5]. In order to achieve a coherent and safe medication therapy in the transfer between primary and secondary care, good communication between health care providers is considered necessary which, however, at present is thought to be inadequate [6]. Often, reasons and argumentation for changes in medication made during hospitalization are insufficiently described in the discharge summary, making it challenging for the general practitioner (GP) to get and maintain an overview of current medication therapy [7-9]. This has been suggested to lead to poor compliance to changes made to the patients' medication during admission $[10,11]$. One potential explanation could be the lack of oral communication between hospital and primary care providers $[8,12,13]$. To enable interprofessional collaboration, both primary and secondary care providers should be involved in implementing medication reviews and organizing their follow-up [14]. Direct communication between hospital and primary care occurs infrequently [9] and telephone conferences between primary and secondary care could be a solution to optimize the oral communication and take action on organizing follow-up in order to implement changes based on medication reviews.

\section{Aim of the study}

The aim of this study was to assess the feasibility of conducting telephone conferences between hospital geriatricians, hospital pharmacists and GPs after discharge of older patients.

\section{Methods}

\section{Study design, patients and setting}

This study was a feasibility study [15] conducted with patients admitted to one of the two departments of Geriatric medicine at Odense University Hospital and Svendborg Hospital, Denmark. The study was initially set up as a controlled study with individual-level randomization, with the control group not receiving a pharmacist intervention. However, this design was abandoned due to challenges in carrying out the intervention resulting in too few telephone conferences. As such, only the feasibility of the study is reported in this paper. This is in line with recommendations for testing complex interventions with a feasibility study before designing a larger trial [16]. Patients were included if they were admitted to the Geriatric ward at one of the two hospitals, 65 years or older, using five or more prescribed drugs on a daily basis (polypharmacy patients), and spoke and understood Danish. Patients were excluded if they were unable to provide informed consent, e.g. due to cognitive impairment (dementia, delirium etc.), died during admission, were transferred to another department or in any other way missed the full intervention at discharge.

Patients were enrolled from February $16^{\text {th }} 2018$ to November $15^{\text {th }} 2018$. Demographics, medication status and residential information as well as activities of daily living assessed by Barthel Index [17] status for all patients were recorded. The patients received a patient-centered medication history and a medication reconciliation by a pharmaconomist (comparable to a pharmacy technician, although with an education of three years) as part of usual care during admission. If the medication history and medication reconciliation were not performed by a pharmaconomist at the time of admission, a pharmacist conducted the medication 
history and the medication reconciliation before the patient was enrolled in the project. This was done for approximately half of all patients.

All data were processed in the online-based Research Electronic Data Capture system REDCap [18] via Open Patient data Explorative Network (OPEN) [19].

\section{Intervention}

No pharmacist was involved in the treatment of the patients at the departments before this study. A structured, patient-centered medication review was conducted by a pharmacist corresponding to the method used in the OPTIMIST study $[20,21]$. The drug related problems and suggestions were categorized by the categories from a national drug related problem database $[22,23]$. The medication review was conducted after the patient was admitted, when laboratory data, e.g. kidney function were available, and the primary medical admission note was written.

After conducting the medication review, the pharmacist wrote a note in the patient's electronic health record describing the patient's current medication and medication changes since hospital admission (Figure 1). This note specified both dose and strength for new medications, deprescribed medications and changed medications, respectively, and was updated at patient discharge. The pharmacist checked for discrepancies between the Shared Medication Record and current medication therapy in the electronic patient record. The Shared Medication Record is a personal profile for the single patient which is integrated in the electronic medical record and provides full access to current medication, updated by the physician who last treated the patient [24]. Changes and discrepancies were communicated to the geriatrician responsible for the patient's discharge. The medication changes and the patient's medication status was sent by the pharmacist to the GP and, if relevant, to the patient's nursing home or home care along with the discharge letter. If possible, the pharmacist participated in the patient's discharge consultation.

Following discharge, the pharmacist arranged a telephone conference, if possible, between the geriatrician, the pharmacist and the GP, to discuss the patient's medication changes and hospitalization. The conclusions of the conference were documented by the pharmacist in the electronic patient record and electronically sent to the GP.

\section{Outcome}

The main outcome was the proportion of telephone conferences conducted out of all patients eligible for telephone conferences. As a supplement to this quantitative outcome, a qualitative study of the practical and professional feasibility of the study, based on the attitudes and perspectives among the geriatricians, pharmacists and GPs, was conducted.

Furthermore, as a process parameter of the feasibility, we evaluated the type of medication changes suggested by the pharmacist, the acceptance rate of the suggestions, and the medication list evaluated by number of changes during hospitalization as well as changes in the medication list two weeks after 
discharge. Data for these endpoints were analyzed based on information from the Shared Medication Record and the electronic patient record.

\section{Qualitative data}

The qualitative data of this study is reported according to COREQ [25] (Appendix). For evaluation of attitudes towards and perspectives on the feasibility of the study, we used a hermeneutic-phenomenological approach, which explores the perspectives of the participants about the telephone conferences openly and incorporates preunderstandings of the researchers to interpret the explored experiences [26,27]. First, geriatricians and pharmacists were invited to participate in separate focus group interviews. An interviewer and a moderator conducted the interviews and took notes (authors $A B$ and TG). Furthermore, individual telephone interviews were conducted with GPs. For practical reasons, two participant could not enter the focus group interviews leading to two face-to-face interviews with a geriatrician and a GP from the project group. A semi-structured interview guide was developed and used to guide the interviews. The topics of the three interview guides were: suitability of the patient group, experience with the intervention, aspects of the interprofesional cooperation and use of the communication form. All interviews were audiotaped and transcribed verbatim by research assistants and hereafter double-checked for fidelity by TG or AB. The qualitative data were analyzed using systematic text condensation according to Malterud [28], which includes an overall impression of data to develop preliminary themes, identifying meaning units and sorting them into codes, condensing the content of each code, and finally synthetizing the condensates to describe the identified themes. The coding was conducted by TG and reviewed by LRN and $A B$ and the analysis of all the interviews was discussed by TG, LRN and $A B$ as an iterative process. Data analysis was conducted using Nvivo 11 (QSR international, Doncaster, Victoria, Australia).

\section{Results}

A total of 113 patients were included in the study. Baseline characteristics of the included patients are presented in Table 1. The median age was 83 years (interquartile range, 77-87 years) and 69 (61\%) were women. In total, 16 patients were excluded, of which two patients withdrew their informed consent but agreed to enter the primary analysis, six patients died during admission, and eight patients were excluded because of transfer to another department. An additional 15 patients received no intervention at discharge because of missing pharmacist capacity and were hence not eligible for telephone conferences, resulting in 82 patients receiving the intervention at discharge (Figure 1). Medication changes and status were sent by the pharmacist to the GP and nursing home or home care for 82 (75\%) patients. A total of 40 out of 82 (49\%) telephone conferences were conducted. All three professional groups; geriatrician, pharmacist and GP, were represented in 34 of the 40 telephone conferences. The main reason for conferences not being conducted (Figure 1) were GPs stating that they did not want to participate $(n=16)$ or not returning calls from the pharmacists $(n=17)$.

Timing of the conducted telephone conferences in addition to the time spent delivering the interventions are displayed in Table 2. 


\section{Medication reviews and medication changes}

The clinical pharmacist conducted medication reviews for 110 of the $113(97 \%)$ patients and suggested 136 medication changes (averaging 1.2 changes per patient). The median time spent on conducting a medication review was 20 minutes. The categorization of changes suggested in the medication reviews is illustrated in Table 3. The most common category of changes suggested in the medication reviews was "Choice of drug" $(n=73 ; 54 \%)$.

A total of $80 \%$ and $60 \%$ of the medication changes were implemented in the Shared Medication Record at discharge by the hospital doctors and two weeks after discharge by the GP, respectively.

\section{Attitudes and perspectives among geriatricians, pharmacists and GPs}

Three focus group interviews were arranged, one with six pharmacists and two with two and three geriatricians from Svendborg and Odense, respectively. One geriatrician and one GP from the project group participated in separate face-to face interviews. The interviews lasted between 20 and 75 minutes. Of 22 invited GPs, six GPs participated in telephone interviews, which lasted between 8 and 22 minutes.

The themes that emerged from the interviews were: Project operations, the telephone conference and crosssectorial collaboration. Table 4 displays the themes and a selection of quotes from the interviews.

\section{Theme 1: Project operation}

\section{The interventions}

The geriatricians thought that general practitioners (GPs) could benefit from the discharge summaries written by the clinical pharmacists, because they provided a good overview. This was supported by a GP.

\section{The patient group}

The geriatricians and clinical pharmacists highlighted that several of the included patients were too uncomplicated to discuss with the GP. According to them, the most suitable patient group would have been patients with multi-morbidity, patients with significant medication changes, cognitively impaired patients as well as the most fragile patients. Additionally, the geriatricians highlighted the importance of including terminal patients, while the pharmacists suggested the inclusion of patients with repeated admissions or those receiving certain risk medications.

The GPs highlighted the fact that they would like to have better information provided by the hospital about patients with multi-morbidity, complex patients, and patients for whom the GP found it difficult to make a future plan.

Introduction of clinical pharmacists in the geriatric ward 
The geriatricians emphasized that the pharmacists supported the cooperation in the ward, as they were available and made sure that the medication process was under control. The geriatricians found that the clinical pharmacists had pointed out some important medication errors. The geriatricians also thought that they could benefit from the clinical pharmacists' knowledge in the doctors conference when they discuss the patients' medication. The geriatricians had been pleased with having the clinical pharmacists in the ward because it gave them the opportunity to ask the pharmacists about many things.

The geriatricians did not recall that the pharmacists dealt with many of the patients and they acknowledged that the pharmacists spent a long time arranging telephone conferences. The clinical pharmacists did not feel that they could show their full potential in the project, because they spent so much time on including patients and scheduling telephone conferences with GPs, and therefore did not get to perform many medication reviews.

\section{Theme 2: The telephone conference}

\section{Barriers and facilitators}

The geriatricians thought that the telephone conferences did not work, because it was too challenging to make a fixed appointment in a busy workday. The clinical pharmacists stated that it could be difficult for both geriatricians and the GPs to find the time and resources for the conferences. According to the GPs, the inflexible appointments meant that they had to take the time off of their patients, and it was not easy to fit in the daily schedule. According to the geriatricians, it is a barrier that general practice and hospitals are organized so differently. Geriatricians, pharmacists and GPs expressed surprise about the fact that it was so difficult to schedule a phone call.

\section{Time and benefit}

Both geriatricians and pharmacists thought that there was a significant waste of time in relation to the telephone conferences compared to the benefit from them, and the geriatricians felt that they were too busy for the telephone conferences. The geriatricians thought that, where uncomplicated patients were concerned, it was unnecessary for both geriatrician and pharmacist to participate in the conversation. Both geriatricians and pharmacists had experienced good telephone conferences, in which the GP expressed to be satisfied with the conference, and that they benefited from the conference.

\section{Implications for the patient}

Overall, the geriatricians felt that the telephone conferences did not have major implications for the patient. While some conferences might have helped the patient a little, it did not save lives. One geriatrician expressed that a patient was re-admitted, even though a telephone conference was conducted, because the patient suffered from other conditions that were not brought up. Sometimes the telephone conference revealed that the patient had not gone for follow-up, or that they should be referred to the outpatient clinic, but it was not medication-related. The geriatricians thought that an explanation in a telephone conference could reduce the risk of medication being resumed without consideration by the GP. 


\section{Theme 3: Cross-sectorial collaboration}

\section{Discharge letters and the Shared Medication Record}

A GP thought that the hospital, sometimes, disclaimed the responsibility by telling the patient, that they could consult their GP regarding a problem, where there was not really much they could do. Sometimes the GPs are unhappy with the fact that patients come to them for prescriptions for which the treatment responsibility lies with the hospital.

\section{Cross-sectorial telephone communication}

The geriatricians thought that the telephone conference could help advance the collaboration, because it was then clearer that the hospital and general practice worked together. GPs are, as a rule, positive towards telephone conferences from the hospital, e.g. concerning complex patients. However, there had to be a stated purpose with the phone call.

\section{Choosing a path of communication across primary and secondary care}

GPs thought that it would be easier to communicate via the telephone, if you were to have a discussion, whereas electronic correspondence messages were particularly useful for specific, non-urgent questions that could be answered relatively easily. According to GPs, it becomes too difficult to answer clarifying questions through written communication, because it is easier to understand and find answers together by talking. However, both paths of communication should only be used when it's relevant, according to GPs.

\section{Discussion}

In this study we tested a multifaceted intervention by establishing telephone conferences to hand over information about changes to geriatric patients' medication from hospital geriatrician and pharmacist to the patients' GP. Our findings suggest that this is possible for half the patients eligible for a telephone conference, although time consuming and difficult to fit in to daily practice, and that prioritization and selection of the right patients is important.

From our findings we believe that the GPs could benefit from the discharge summary from the pharmacists but the gold standard aiming to improve patient handovers from hospital to primary care are multifaceted.

\section{Medication reviews and medication changes}

In this study, 110 of $113(97 \%)$ patients received a medication review, which indicates that a medication review is possible under the given circumstances, and shows that this structured method is feasible. The time spent on conducting a medication review (median 20 minutes) is a reasonable time frame and in accordance with the findings of a prior study, that reported a mean of 26 minutes [20]. The acceptance rate of $80 \%$, which is high compared to previous literature [29], implies that the findings are clinically relevant. 


\section{Attitudes and perspectives among geriatricians, pharmacists and GPs}

Our findings suggest that the different organization of hospital and primary healthcare and coordination between these is one of the main barriers to implementing cross-sectorial telephone conferences, e.g. difficulties in scheduling an appointment across the primary and secondary care in a busy workday. Furthermore, summer vacation was the main reason for the relatively high number of weekdays $($ median $=9)$ between patient discharge and the conducted telephone conferences. Holleck et al. [31] also mention the time frame of the telephone conferences and GPs' vacations as challenging, and found that only $39 \%$ of the GPs in their study wanted an automatic follow-up appointment within two weeks of discharge.

Different organization and procedures across primary and secondary care are difficult to change, but it is required, according to our findings, in order to establish quick cross-sectorial contact. Phipps et al. report that there are a number of technical and organizational challenges to medication management, and that meeting these challenges involves decision-making, planning and team coordination [32].

The geriatricians in our study believed that the GPs could benefit from the discharge summary from the pharmacists because it provided a good overview of the changes made in the patient's medication. This view was supported by some GPs. However, the gold standard aiming to improve patient handovers from hospital to primary care are multifaceted [33]. As an example, a randomized controlled trial assessed the impact of a 'pharmacist transition coordinator' on medication management and health outcomes in older adults undergoing transfer from a hospital to a long-term care facility, reported improved aspects of inappropriate use of medicines across primary and secondary care [34]. This intervention included medication-management transfer summaries from hospitals, coordinated medication reviews by accredited community pharmacists, and case conferences with general practitioners and pharmacists [34]. Another example reported on the use of a structured medication reconciliation form, in many ways similar to our discharge summary, as an example of good practice in relation to primary health care providers' adherence with medication adaptions and recommendations [35]. This complies with the requests from the GPs for reasons and explanations for medication changes and recommendations according to the results from a qualitative Danish study [8].

\section{Strengths and limitations}

The main strengths of this study are the development of the multifaceted intervention and the mix of quantitative and qualitative data that supplement each other in order to assess the feasibility of the intervention and the attitudes and perspectives in relation to it. Another strength of this study is the fact that all interviews were reviewed and double-checked for fidelity by two authors. Finally, the analysis was performed using an established method for synthesizing qualitative data [28].

The study also has several weaknesses. First, the randomization of the planned RCT was not completed due to the challenges in providing an adequate amount of telephone conferences. Second, the telephone interviews were relatively short which could mean that the data generated was not as rich as they could have been. However, this reflects very well the busy daily setting of the GPs and is also one the reasons why only

Page $10 / 19$ 
six of the 22 invited GPs participated in telephone interviews. Another limitation is the fact that patients with severe dementia and delirium were not represented in our population because of the requirements for informed consent. Future research should assess whether patients with dementia or cognitive impairment could benefit from a telephone conference because of the diminished capability of bringing a message across primary and secondary care on account of their diagnosis. Unfortunately we did not register how many of the patients who had a telephone conferences and on behalf of that had changes implemented. This also could be a topic of future research. As the electronic patient record system is only designed for one-way communication, it is not ideal for handling complex questions or dialogue, and other communication systems might have to be developed and tested.

\section{Conclusion}

Telephone conferences between geriatricians, GPs and pharmacists were possible for half of the patients. The geriatricians, pharmacists and GPs agreed that telephone conferences were only relevant and useful when the patients were complex. Under the given circumstances in the present clinical Danish setting, it was difficult to establish a telephone conference between geriatrician, pharmacist and GP due to practical issues, timing and prioritizing.

\section{Declarations}

\section{Acknowledgements}

Kim Brixen, Head of Odense University Hospital and Lisbeth Muurholm, Head of Hospital Pharmacy Funen ensured the organizational base for performing the study and we are indebted to them. We would like to thank the intervention pharmacists from Odense University Hospital and Svendborg Hospital and the rest of the personnel involved from the Hospital Pharmacy of Funen. We would also like to thank the participating geriatricians, patients, nurses and all the GPs.

\section{Funding}

This study was supported by unrestricted grants from the Ministry of Health in Denmark under Grant number 1704197.

\section{Conflicts of interest}

Lene V. Ravn-Nielsen, Alaa Burghle, Palle M. Christensen, Faruk Coric, Trine Graabæk, Fjóla Karlsdóttir, Jolene P. Henriksen, Jens-Ulrik Rosholm and Anton Pottegård report no conflicts of interest.

\section{Ethics approvals}

Each included patient provided written informed consent. In terms of data protection, the study was registered at the Odense University Hospital's inventory (record no. 17/37441). Finally, the study was registered at clinicaltrial.gov (NCT03369652). The National Committee on Health Research Ethics waived to assess the study protocol. 


\section{References}

1. Midlov P, Bergkvist A, Bondesson A, Eriksson T, Hoglund P. Medication errors when transferring elderly patients between primary health care and hospital care. Pharm World Sci. 2005 Apr;27(2):116-20.

2. Christensen HR, Krølner BK. [Medication problems in connection with transferral between sectors]. Ugeskr Laeg. 2009 Mar 2;171(10):808-11.

3. Kripalani S, Jackson AT, Schnipper JL, Coleman EA. Promoting effective transitions of care at hospital discharge: a review of key issues for hospitalists. J Hosp Med. 2007 Sep;2(5):314-23.

4. Coleman EA, Smith JD, Raha D, Min S. Posthospital medication discrepancies: prevalence and contributing factors. Arch Intern Med. 2005 Sep 12;165(16):1842-7.

5. Parekh N, Ali K, Page A, Roper T, Rajkumar C. Incidence of Medication-Related Harm in Older Adults After Hospital Discharge: A Systematic Review. Journal of the American Geriatrics Society. 2018;66(9):181222.

6. Vermeir P, Vandijck D, Degroote S, Peleman R, Verhaeghe R, Mortier E, et al. Communication in healthcare: a narrative review of the literature and practical recommendations. International Journal of Clinical Practice. 2015 Nov;69(11):1257-67.

7. Lehn SF, Zwisler A-D, Pedersen SGH, Gjørup T, Thygesen LC. Patient-specific versus Organisational Barriers to Program Adherence: A Multivariate Analysis. Int J Integr Care. 2019 Mar 15;19(1):7.

8. Strehlau AG, Larsen MD, Søndergaard J, Almarsdóttir AB, Rosholm J-U. General practitioners' continuation and acceptance of medication changes at sectorial transitions of geriatric patients - a qualitative interview study. BMC Fam Pract. 2018 Oct 12;19(1):168.

9. Kripalani S, LeFevre F, Phillips CO, Williams MV, Basaviah P, Baker DW. Deficits in communication and information transfer between hospital-based and primary care physicians: implications for patient safety and continuity of care. JAMA. 2007 Feb 28;297(8):831-41.

10. Larsen MD, Rosholm JU, Hallas J. The influence of comprehensive geriatric assessment on drug therapy in elderly patients. European Journal of Clinical Pharmacology. 2014 Feb;70(2):233-9.

11. Redmond P, McDowell R, Grimes TC, Boland F, McDonnell R, Hughes C, et al. Unintended discontinuation of medication following hospitalisation: a retrospective cohort study. BMJ Open. 2019 Jun;9(6):e024747.

12. Allen J, Ottmann G, Roberts G. Multi-professional communication for older people in transitional care: a review of the literature. International Journal of Older People Nursing. 2013;8(4):253-69.

13. Jones CD, Vu MB, O'Donnell CM, Anderson ME, Patel S, Wald HL, et al. A Failure to Communicate: A Qualitative Exploration of Care Coordination Between Hospitalists and Primary Care Providers Around Patient Hospitalizations. J GEN INTERN MED. 2015 Apr;30(4):417-24.

14. Walraven B. Medication reviews in hospitalized patients: a qualitative study on perceptions of primary and secondary care providers on interprofessional collaboration. 2020;10.

15. Eldridge SM, Chan CL, Campbell MJ, Bond CM, Hopewell S, Thabane L, et al. CONSORT 2010 statement: extension to randomised pilot and feasibility trials. :29.

16. Bowen DJ, Kreuter M, Spring B, Cofta-Woerpel L, Linnan L, Weiner D, et al. How We Design Feasibility Studies. American Journal of Preventive Medicine. 2009 May;36(5):452-7. 
17. Law M, Letts L. A Critical Review of Scales of Activities of Daily Living. Am J Occup Ther. 1989 Aug $1 ; 43(8): 522-8$.

18. Harris PA, Taylor R, Thielke R, Payne J, Gonzalez N, Conde JG. Research electronic data capture (REDCap)-a metadata-driven methodology and workflow process for providing translational research informatics support. J Biomed Inform. 2009 Apr;42(2):377-81.

19. OPEN - University of Southern Denmark, SDU [Internet]. SDU. [cited 2019 Oct 24]. Available from: https://www.sdu.dk:443/en/om_sdu/institutter_centre/klinisk_institut/forskning/forskningsenheder/open

20. Ravn-Nielsen LV, Duckert M-L, Lund ML, Henriksen JP, Nielsen ML, Eriksen CS, et al. Effect of an InHospital Multifaceted Clinical Pharmacist Intervention on the Risk of Readmission: A Randomized Clinical Trial. JAMA Internal Medicine. 2018 Mar 1;178(3):375.

21. Graabæk T, Bonnerup DK, Kjeldsen LJ, Rossing C, Pottegård A. Pharmacist-led medication review in an acute admissions unit: a systematic procedure description. European Journal of Hospital Pharmacy. 2015 Jul;22(4):202-6.

22. Kjeldsen LJ, Birkholm T, Fischer H, Graabæk T, Kibsdal KP, Ravn-Nielsen LV, et al. Characterization of drugrelated problems identified by clinical pharmacy staff at Danish hospitals. Int J Clin Pharm. 2014 Aug $1 ; 36(4): 734-41$.

23. Kjeldsen LJ, Birkholm T, Fischer H, Graabæk T, Hansen MK, Kibsdal KP, et al. A national drug related problems database: evaluation of use in practice, reliability and reproducibility. Int J Clin Pharm. 2014 Aug 1;36(4):742-9.

24. Munck LK, Hansen KR, Mølbak AG, Balle H, Kongsgren S. The use of shared medication record as part of medication reconciliation at hospital admission is feasible. 2014;5.

25. Tong A, Sainsbury P, Craig J. Consolidated criteria for reporting qualitative research (COREQ): a 32-item checklist for interviews and focus groups. Int J Qual Health Care. 2007;19(6):349-57.

26. Laverty SM. Hermeneutic Phenomenology and Phenomenology: A Comparison of Historical and Methodological Considerations. International Journal of Qualitative Methods. 2003 Sep 1;2(3):21-35.

27. Malterud K. Theory and interpretation in qualitative studies from general practice: Why and how?: Scandinavian Journal of Public Health [Internet]. 2015 Dec 8 [cited 2020 Sep 17]; Available from: https://journals.sagepub.com/doi/10.1177/1403494815621181?url_ver=Z39.882003\&rfr_id=ori\%3Arid\%3Acrossref.org\&rfr_dat=cr_pub++0pubmed

28. Malterud K. Systematic text condensation: a strategy for qualitative analysis. Scand J Public Health. 2012 Dec;40(8):795-805.

29. Graabaek T, Kjeldsen LJ. Medication Reviews by Clinical Pharmacists at Hospitals Lead to Improved Patient Outcomes: A Systematic Review. Basic \& Clinical Pharmacology \& Toxicology. 2013 Jun;112(6):359-73.

30. Rouch L, Farbos F, Cool C, McCambridge C, Hein C, Elmalem S, et al. Hospitalization Drug Regimen Changes in Geriatric Patients and Adherence to Modifications by General Practitioners in Primary Care. J Nutr Health Aging. 2018;22(3):328-34.

31. Holleck JL, Gunderson CG, Antony SM, Gupta S, Chang JJ, Merchant N, et al. The 'Hand-in' Project: Jumpstarting Communication Between Inpatient and Outpatient Providers. South Med J. 2017;110(11):694-8. 
32. Phipps DL, Morris RL, Blakeman T, Ashcroft DM. What is involved in medicines management across care boundaries? A qualitative study of healthcare practitioners' experiences in the case of acute kidney injury. BMJ Open. 2017 Jan 1;7(1):e011765.

33. Hesselink G, Schoonhoven L, Barach P, Spijker A, Gademan P, Kalkman C, et al. Improving patient handovers from hospital to primary care: a systematic review. Ann Intern Med. 2012 Sep 18;157(6):41728.

34. Crotty M, Rowett D, Spurling L, Giles LC, Phillips PA. Does the addition of a pharmacist transition coordinator improve evidence-based medication management and health outcomes in older adults moving from the hospital to a long-term care facility? Results of a randomized, controlled trial. The American Journal of Geriatric Pharmacotherapy. 2004 Dec;2(4):257-64.

35. Dumur J, Chassagne P, Gbaguidi X, Csajka C, Chassagne P, Lang PO. Using a structured reconciliation medication form improves medication transition from hospital to community care and primary care physicians' adherence with medication adaptations and recommendations. European Geriatric Medicine. 2019 Feb;10(1):141-6.

36. Mitchell G, Cherry M, Kennedy R, Weeden K, Burridge L, Clavarino A, et al. General practitioner, specialist providers case conferences in palliative care--lessons learned from 56 case conferences. Aust Fam Physician. 2005 May;34(5):389-92.

37. Allen J, Ottmann G, Brown R, Rasmussen B. Communication pathways in community aged care: an Australian study. Int J Older People Nurs. 2013 Sep;8(3):226-35.

38. Borgsteede SD, Karapinar-Çarkit F, Hoffmann E, Zoer J, van den Bemt PMLA. Information needs about medication according to patients discharged from a general hospital. Patient Educ Couns. 2011 Apr;83(1):22-8.

\section{Tables}

Table 1. Patient characteristics of the 113 patients included at baseline. Patients were recruited in the Geriatric wards of Odense University Hospital and Svendborg Hospital. 


\begin{tabular}{|ll|}
\hline $\mathbf{n}=113$ & $\mathbf{n}(\%)$ \\
\hline Men & $44(39)$ \\
\hline Women & $69(61)$ \\
\hline Age, median (IQR) & $83(77-87)$ \\
\hline Number of medications by admission, median (IQR) & $11(8-15)$ \\
\hline Number of medications by discharge, median (IQR) & $12(9-16)$ \\
\hline Residential status & $9(8)$ \\
\hline Nursery home/rehabilitation home & $69(61)$ \\
\hline Own home living alone & $35(31)$ \\
\hline Own home with relatives & $81(72)$ \\
\hline Medication administration status & $7(6)$ \\
\hline Self-administrating patients & $25(22)$ \\
\hline Patients with unit dose drug dispensing & $48(36-69)$ \\
\hline Patients with help from nurse to medication management & 25 (1) \\
\hline Barthel Index* median (IQR) & \\
\hline
\end{tabular}

* Data available for 83 patients

Abbreviation: IQR, interquartile range.

Table 2. Timing of telephone conferences and time spent on interventions for the 110 patients in the Geriatric ward at Odense University Hospital and Svendborg Hospital.

\begin{tabular}{|ll|}
\hline $\mathrm{n}=110$ & Median (range) \\
\hline No. of workdays after discharge until telephone conferences where conducted (days) & $9(1-34)$ \\
\hline Time spent per medication review (minutes) & $20(5-120)$ \\
\hline Time spent per sent correspondence to GP inclucluding preparation (minutes) & $20(5-60)$ \\
\hline Time spent per telephone conference including preparation (minutes) & $20(2-90)$ \\
\hline
\end{tabular}

Table 3. Categorization of changes suggested in the medication reviews for 110 patients in the Geriatric ward at Odense University Hospital and Svendborg Hospital. 
Choice of drug (contraindication, no indication for treatment, interactions, therapeutic duplication, more optimal choice of drug, preventive treatment is missing, new indication)

Dose (too high/too low, wrong dosage interval, lack of monitoring)

Duration of treatment (too long/too short)

Administration (time of administration, drug not administrated, wrong drug administrated, drug abuse, the patient cannot use the drug)

Logistics (the drug is not accessible, mistake in the prescription, mistake in dispensing, medication reconciliation or SMR/EPR related mistakes)

Patient related (patient forgets to take the medicine, patient stored the medication wrong)

Other

Total

Abbreviations: SMR, Shared Medication Record and EPR, Electronic Patient Record

Table 4 Schematic example of the steps in the analysis from meaning units to main themes 


\begin{tabular}{|c|c|c|c|}
\hline Meaning units & Condensation & Sub theme & Main theme \\
\hline $\begin{array}{l}\text { "But here you had the reasons for it } \\
\text { [medication changes] and [...] it was } \\
\text { very clear, as I remember, that it was } \\
\text { stated, something along the lines of } \\
\text { which specific changes were done, } \\
\text { while a standard discharge summary } \\
\text { does not necessarily mention which } \\
\text { three medications were changed, } \\
\text { specifically. You kind of have to figure } \\
\text { that out yourself, so it gave a better } \\
\text { overview." (GP 7) }\end{array}$ & $\begin{array}{l}\text { In the new discharge letter, } \\
\text { there were reasons for } \\
\text { medication changes listed } \\
\text { along with specific } \\
\text { medication changes, which } \\
\text { you sometimes have to } \\
\text { figure out yourself in a } \\
\text { standard discharge } \\
\text { summary, and it provided a } \\
\text { better overview. }\end{array}$ & $\begin{array}{l}\text { The } \\
\text { interventions }\end{array}$ & $\begin{array}{l}\text { Project } \\
\text { operation }\end{array}$ \\
\hline $\begin{array}{l}\text { "It [the challenge] could be with multi- } \\
\text { morbidity, where the patient suffers } \\
\text { from many diseases and sometimes } \\
\text { the question is, like, how much or how } \\
\text { little do you need to follow up on the } \\
\text { different issues [...]if we subsequently } \\
\text { receive them [after discharge], we } \\
\text { could end up doing many blood tests } \\
\text { for things that should not have been } \\
\text { checked, and you could say, that you } \\
\text { put down a specific plan for, what to } \\
\text { follow up on and what not to, what is } \\
\text { being followed up at the hospital and } \\
\text { what do we have to follow up on" (GP } \\
\text { 2) }\end{array}$ & $\begin{array}{l}\text { The relevant patient group } \\
\text { for the project would be the } \\
\text { ones with multi-morbidity } \\
\text { because the question is how } \\
\text { much you need to follow up, } \\
\text { as we can end up doing } \\
\text { many unnecessary blood } \\
\text { tests, so it could be } \\
\text { beneficial to have a focused } \\
\text { plan. }\end{array}$ & $\begin{array}{l}\text { The patient } \\
\text { group }\end{array}$ & $\begin{array}{l}\text { Project } \\
\text { operation }\end{array}$ \\
\hline \multirow[t]{2}{*}{$\begin{array}{l}\text { "But we have used you to answer } \\
\text { questions and issues that were } \\
\text { present; it has been nice to have a } \\
\text { lexicon walking around [the ward].” } \\
\text { (Geriatrician 6) }\end{array}$} & $\begin{array}{l}\text { We have used you to answer } \\
\text { present questions, and it } \\
\text { was nice to have a lexicon } \\
\text { available at the ward. }\end{array}$ & $\begin{array}{l}\text { Introduction of } \\
\text { clinical } \\
\text { pharmacists in } \\
\text { the geriatric } \\
\text { ward }\end{array}$ & $\begin{array}{l}\text { Project } \\
\text { operation }\end{array}$ \\
\hline & $\begin{array}{l}\text { In my view, the problem is } \\
\text { mainly administrative and } \\
\text { organizational rather than } \\
\text { professional. }\end{array}$ & $\begin{array}{l}\text { Barriers and } \\
\text { facilitators }\end{array}$ & $\begin{array}{l}\text { The } \\
\text { telephone } \\
\text { conference }\end{array}$ \\
\hline $\begin{array}{l}\text { "I think, that [the issues] I spoke with } \\
\text { the GP about, are things that she [the } \\
\text { pharmacist] might as well have talked } \\
\text { with the GP about, there was no } \\
\text { reason for us both to be there." } \\
\text { (Geriatrician 5) }\end{array}$ & $\begin{array}{l}\text { There was no reason for } \\
\text { both the pharmacist and the } \\
\text { geriatrician to be present at } \\
\text { the consultation with the } \\
\text { general practitioner, the } \\
\text { pharmacist could have had } \\
\text { the consultation alone or I } \\
\text { could. }\end{array}$ & $\begin{array}{l}\text { Time and } \\
\text { benefit }\end{array}$ & $\begin{array}{l}\text { The } \\
\text { telephone } \\
\text { conference }\end{array}$ \\
\hline $\begin{array}{l}\text { "I think that, maybe, it is of } \\
\text { importance for the medication } \\
\text { therapy if you have a conversation } \\
\text { where you, with words. Explain that } \\
\text { this and this [medication] have been } \\
\text { discontinued for this or that reason. } \\
\text { Then I think that the risk of it [the } \\
\text { medication] being resumed without } \\
\text { consideration would be lower." } \\
\text { (Geriatrician 1) }\end{array}$ & $\begin{array}{l}\text { I think the risk for } \\
\text { medication to be resumed } \\
\text { without consideration at the } \\
\text { general practitioner is lower } \\
\text { if you have been told which } \\
\text { specific medication have } \\
\text { been discontinued and for } \\
\text { what reason. }\end{array}$ & $\begin{array}{l}\text { Implications for } \\
\text { the patient }\end{array}$ & $\begin{array}{l}\text { The } \\
\text { telephone } \\
\text { conference }\end{array}$ \\
\hline
\end{tabular}


"And therefore they should align their medication lists from there [the hospital] and write the missing prescriptions, because I do not have any chance of knowing what has happened in there [the hospital], specifically if the answer comes a little later. So there is that, and then there is the good nurse who says [to the patient], on their way out, that they can just go to their general practitioner and get it fixed, those I also reject. But I've had some [cases] where I just thought 'this isn't good enough'." (GP 6)

"Generally, my position is that I am positive towards this collaboration around complex patients." (GP 3)

"No, I think, generally, that people are positive if you contact them, and I hope that we are as well, when we are contacted here sometimes. It's not something to be used at any time, the telephone, I mean, neither are electronic correspondence messages, unless it's something you can't solve yourself, because we're all busy. But I do think that we are good at helping each other, mostly." (GP 3)
The hospital should align their medication lists and write the missing prescriptions, because I do not have any chance of knowing what has happened in the hospital, especially if the discharge letter comes a little later. There is the good nurse, who says to the patient on their way out that they can just go to their general practitioner and get their prescription, but I reject those.
Discharge

letters and the

Shared

Medication

Record
Crosssectorial collaboration
I am positive towards collaboration around complex patients.

In general, I think people are positive if you contact them, and I hope that we are as well, when we are contacted here sometimes. I think that you should not use the telephone or electronic correspondence messages at any time, unless it is something that you cannot solve yourself, because we are all busy. I think we are mostly good at helping each other.

\section{Figures}




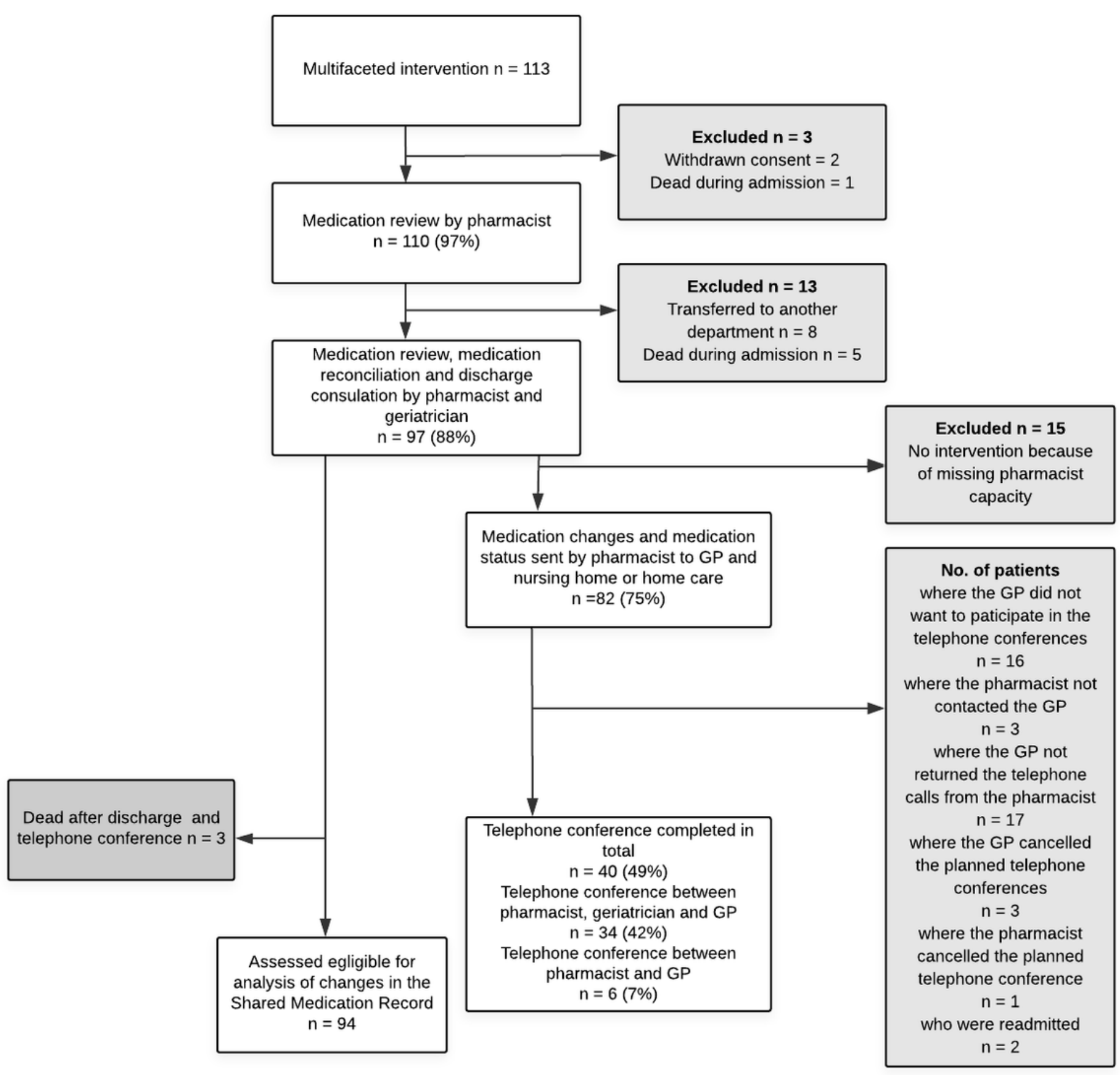

Figure 1

Diagram of intervention and patient flow for 113 patients in the Geriatric ward at Odense University Hospital and Svendborg Hospital.

\section{Supplementary Files}

This is a list of supplementary files associated with this preprint. Click to download.

- AppendixCOREQ20210309.docx 